\title{
El cogito y la conciencia Lo escópico y las particularidades del mundo onírico
}

\author{
The Cogito and consciousness \\ The scopic field and traits of the oneiric world
}

\section{Bruno Carignano}

\section{RESUMEN:}

El objetivo del artículo es analizar los estatutos del cogito y de la conciencia desde el punto de vista escópico, en la disyunción entre vida diurna y experiencia onírica. La metodología, de tipo teórico, consiste en el análisis de algunos textos filosóficos y psicoanalíticos a partir de una serie de problemas esbozados. Comenzamos por interrogar el lugar argumental del sueño en la concepción de una conciencia heterótopa, apoyándonos en teorizaciones de Lacan y Sartre; el fin es avanzar sobre la dificultad de pensar una conciencia no unitaria, por el enmascaramiento que el yo produce. Como contrapartida, el fenómeno onírico es un argumento crucial para concebir una conciencia sin yo. La discrepancia del lugar del cogito respecto del sueño y la locura nos allana el camino para mejor dilucidar la relación entre cogito y sueño. Desbrozamos luego el planteo del mundo como omnivoyeur pero no exhibicionista a partir de las distinciones efectuadas. Concluimos que el sueño como fenómeno escópico debe circunscribirse a la ausencia de soporte narcisista como anclaje de un sujeto, pues el sujeto geometral cartesiano
SUMMARY:

The objective of this paper is to analyze the status of both consciousness and the cogito, from the point of view of the scopic field. To accomplish it, we examine the differences between waking life and oneiric experience. Methodology is theoretical, it consists on the analysis of several psychoanalytic and philosophical works. First of all, we interrogate the idea of dream as an argument for the conception of an heterotopic consciousness, taking into account both Lacan's and Sartre's theories. Our aim is to approach the problem of a non unitary consciousness, related to the disguising that the ego produces. As a counterpart, oneiric phenomenon is a crucial argument to support the conception of a consciousness without an ego. Discrepancy of the cogito between dream and madness lead us to conceive, from another angle, the relation between dream and the cogito. Afterwards, we analyze the idea of a voyeuristic but not exhibitionist world. We conclude that dream should be linked, as a scopic phenomenon, to the absence of a narcissistic support for the subject. The geometrical-Cartesian subject appears 
está diseminado en las imágenes del spread among the images of the dream, the sueño; la captación del cogito cartesiano es, pues, sólo escópica en el sentido restringido de la vida diurna.

\section{Palabras Clave:}

El cogito - conciencia - narcisismo sueño - campo escópico cogito apprehension is then just scopic in the restricted sense of the waking life.

\section{WORD PAD:}

The cogito - consciousness - narcissism dream - scopic field. 
Un rêve, c'est conscient.

\section{J. LACAN}

El Cogito afirma demasiado. El contenido cierto del pseudo "Cogito" no es "yo tengo conciencia de esta silla", sino "hay conciencia de esta silla". J.-P. SARTRE

Il n'y a pas, dans un monde imaginaire, rêve des possibilités. J.-P. SARTRE

\section{INTRODUCCIÓN: EL SUJETO DE LA REPRESENTACIÓN Y EL NARCISISMO}

La categoría de representación posee un vestigio idealista que Lacan circunscribe muy bien. El sujeto de la representación, que puede ser concebido como un síntoma de cierta concepción idealista ${ }^{1}$, exige considerar, en el campo psicoanalítico, el problema del narcisismo.

Existe un enraizamiento narcisista del pensamiento que supone una especie de imantación en torno al sujeto de la representación, lo que implicaría taponar el agujero que el objeto a produce al narcisismo. Aunque el lugar sintético del sujeto como lo que unifica la pluralidad de imágenes (representaciones) que del exterior ingresan por el agujero en ese esquema que Lacan califica de berkelyano — "esa maravillosa estupidez de la síntesis de la conciencia que está en alguna parte" (LACAN, [I968-69], 2006: 289)- deba, como error teórico, ser terminantemente rechazado, ello no impide que en cierto registro opere; pues no se trata de otra cosa que de los efectos del narcisismo sobre el pensamiento.

Si el sueño presenta una importancia clave en el desarrollo que hemos de efec- tuar es porque en la disolución narcisista del mundo onírico nos encontramos con un pensamiento desembarazado de toda referencia al sujeto de la representación, como lo veremos en los desarrollos de este artículo. En el sueño no vemos más que los rastros de un narcisismo disuelto. Por el contrario, en el pensamiento diurno, nos encontramos con la resistencia del narcisismo - en nombre del sujeto de la representación- a dejarse disolver enteramente por la impersonalidad del pensamiento inconsciente. Algo del narcisismo insiste en no dejarse absorber por el pensamiento; interpretamos, pues, la formulación de que "el pensamiento es de por sí censura" (LACAN, [I968-69], 2006, pp.290-9I) en el sentido siguiente: es censura por la referencia a un sujeto de la representación que tapona el lugar estructural del objeto a como agujero del narcisismo.

El pensamiento de la vida diurna difícilmente deje de escapar plenamente a la inercia del yo (je), mientras que en el sueño no hay ningún existente que pueda decir yo (je). En el abordaje que aquí llevaremos a cabo consideramos que la diferencia se plantea entre un pensamiento imantado por el narcisismo (aunque no se reduzca de ningún modo a ello, sino no habría psicoanálisis) y un pensamiento - el onírico- que por su estructura lo excluye.

De acuerdo con Le Gaufey, el mundo de la representación se encuentra sostenido en la idea de que "la unidad del perceptum es como el reflejo directo de la unidad por fuera de toda sospecha del percipiens" (LE GAufey, I997, p.274). De ello, este autor deduce algo fundamental para lo que nos ocupa: que el sujeto que se desprende de ese carácter unitario del percipiens no es otro que el ego. Según su planteo, el reco- 
rrido de Lacan sería, pues, profundamente anticartesiano porque "el sujeto cartesiano no es más que el otro polo de una representación" que poco tiene que ver con el inconsciente (Le Gaufey, I997, p.275).

Aquí, más que situar el evidente anticartesianismo de Lacan que supone la refundación del inconsciente freudiano, nos interesa mostrar que, en principio, el cartesianismo del cogito es consubstancial a la estructura narcisista del mundo de vigilia. Pero además quisiéramos, por otra parte, dilucidar cuál es el estatuto de una conciencia que excede al pensamiento meditante del cogito, una conciencia que va más allá del ego (del cual el cogito cartesiano no parece poder liberarse).

En el afán de teorizar ese modo de conciencia que rebasa al cogito confluyen los esfuerzos de Lacan y Sartre; ambos lo consiguen desprendiendo a la conciencia del ego. Como lo veremos, qué quiere decir una conciencia sin yo, es algo que sólo podremos concebir a partir de la experiencia onírica.

\section{Desprendimiento DE YO Y CONCIENCIA EN LACAN Y SARTRE. El valor argumental de la conciencia del sueño}

Para comenzar, ubicamos dos momentos diferentes en la teorización de Lacan sobre la conciencia y las objeciones a sus embustes de autonomía:

1) Tempranamente, la pretendida autonomía de la conciencia es cuestionada por construirse en función del desconocimiento yoico. Es el caso de algunas objeciones dirigidas a Sartre (y también a Freud) en "El estadio del espejo como formador de la función del yo $[\mathrm{Je}]$...”. Allí sostiene que la filosofía del ser y la nada "encadena a los desconocimientos constitutivos del yo la ilusión de autonomía en que [la conciencia] se confía"(LACAN, [I949], I97I: 98). De todas formas, ya puede allí percibirse un deslizamiento, desde la explícita objeción del estatuto de la conciencia en Sartre al cuestionamiento de cierta versión realista de la conciencia, la que se funda en un prejuicio cientificista (dentro de lo que se enmarca su ataque a la concepción freudiana de un yo asentado en el sistema percepción-conciencia). Esta es la línea que se prosigue en los primeros años de su enseñanza. Nos centraremos especialmente en los desarrollos del segundo seminario; ellos permiten ver, marginalmente, cómo se matiza allí la crítica a este filósofo, en cuyos argumentos Lacan parece apoyarse para atacar otra vez a una versión cientificista y evolucionista de la conciencia, que de ningún modo podría ser la Sartre. La reivindicación que allí efectúa del término contingencia para pensar la conciencia, en contra de la superioridad del hombreen el mundo que la necesidad evolucionista proclama, es sugerente al respecto (LACAN, I954-55 b, p.88).

2) En un segundo momento, que localizamos tomando como referencia tanto el escrito "Subversión del sujeto..." como el seminario La angustia, la alienación de la conciencia se circunscribe en referencia a los objetos $a$, que no tienen imagen especular. En el primero, los objetos parciales son caracterizados como la tela o el forro, aunque, como se lo especifica, ello no implica que sean el reverso del sujeto "que se toma por el sujeto de la conciencia". Lo que allí se plantea no deja de estar en continuidad con lo esbozado tempranamente, puesto que, como luego se lo hace explícito, "es a este objeto incaptable en el espejo que la imagen especular da su vesti- 
menta" (LACAN, [I960], I97I, p.I80). En el seminario La angustia, al reconocerse el "comienzo de solución" que representa lo avanzado en "El estadio del espejo...", se propone un paso más: situar el origen real del sistema de la conciencia a partir del objeto $a$, ese "objeto aislable, especificado en la estructura” (LACAN [1962-63], 2004, p.79).

Lacan está lejos de desconocer todos los avances de Sartre respecto del desprendimiento ego-conciencia en La transcendencia del ego. Todo lo contrario, tiene muy en cuenta dicho ensayo, al punto de que le sirve de referencia fundamental en las primeras clases del seminario El yo en la teoría de Freud y en la técnica psicoanalítica. En la quinta sesión se refiere explícitamente a la manera en que, desde el punto de vista existencialista, se produce el desamarre entre "la captación de la conciencia por sí misma [...]" y "la captación existencial del yo (moi)" (LACAN, [I95455a], I978, p.84). Encontramos aquí el marco general para situar una coincidencia entre ambos autores; sin embargo, si la cuestión no puede dirimirse tan rápidamente, es porque hay diferentes niveles a examinar que la complejizan.

Ante todo, cabe mencionar lo que pareciera ser una clara deuda de Lacan para con Sartre en sus bosquejos teóricos sobre la conciencia. Aquél no habría podido avanzar del modo en que lo ha hecho si el segundo no hubiera sentado las bases de la disyunción con algunas precisiones fundamentales en La trascendencia del ego, que podrían resumirse en estas líneas: “[...] jamás podré decir $m i$ conciencia, o sea la conciencia de mi yo" (SARTRE, [I936], p.IO2); "[...] la conciencia trascendental es una espontaneidad impersonal" (SARTRE, [I936], p.IO4).
En los cuestionamientos dirigidos a cierta concepción de la conciencia puede verse que no es Sartre el foco explícito de las objeciones de Lacan, sino una versión evolucionista de la primacía de la conciencia - "perspectiva clásica tradicional de la conciencia considerada como acabamiento del ser" (LACAN, I 954-55 b, p.87)-, asociada a ese "antropomorfismo tan delirante", que no es otro que el de la "necedad del ateísmo cientificista” (LACAN, I954-55b, p.86). Lacan busca contrarrestar los efectos de esta concepción evolucionista, precisamente apoyándose en una categoría de mucho peso en Sartre, la de contingencia, como más arriba lo precisamos: "sabemos que la conciencia está ligada a algo totalmente contingente, tan contingente como la superficie de un lago en un mundo inhabitado" (LACAN, I954-55 b, p.88). Esta figura seráde relieve para dar consistencia al apólogo que intenta dilucidar la especificidad del fenómeno de conciencia.

Pese a estas salvedades, Lacan parece insinuar que, de todas maneras, en la concepción sartreana de conciencia, se filtraría algo que no debe propiamente adscribirse a la conciencia, sino al ego. Pero esto, lejos de contradecir a Sartre, ¿no nos lleva, por el contrario, a encontrar una confluencia con su planteo de "un lazo indisociable entre conciencia y yo a partir de una unión originaria?" (VASSALLO, 20I3, p.6I).

Para Sartre, la espontaneidad de la conciencia irreflexiva (irréflechie) supone una unidad ${ }^{2}$, mientras que Lacan pretende despojar a la conciencia de todo aspecto unitario, porque considera que ello tiene su origen en los desconocimientos del ego. A la supuesta unidad de la conciencia la cuestiona oponiéndole su temprana distinción entre la captación unitaria del yo en su imagen especular y su contracara, 
la fragmentación en la experimentación del propio cuerpo, es decir, la dimensión pulsional del autoerotismo como opuesta al narcisismo. Creemos que la diferencia entre " $[\ldots]$ cierto nivel de las tendencias que son experimentadas [...] como desconectadas, como discordantes, como despedazadas" y "[...] eso en lo cual el sujeto por la primera vez se conoce como unidad, pero como unidad alienada, como unidad virtual" (LACAN, [I954-55b],pp.9 I-92), le sirve a Lacan para argumentar que el cuerpo que se acopla a una captación consciente no tiene necesariamente un aspecto unitario, porque ese carácter lo da sólo el soporte del yo narcisista.

El punto a considerar es, entonces, si es legítimo objetar a Sartre una unidad de la conciencia independiente del acto reflexivo en que irrumpe el ego. Al comienzo de su ensayo, Sartre expone que "en el plano irreflejo [irréflechi] no hay yo" (SARTRE, [1936], p.48), mientras que sobre el final, arriba a la idea de que "es, sin embargo, cierto que el Yo aparece en el plano irreflejo [irréflechi]" (SARTRE, [I936], p.9I). ¿Hay o no hay, entonces, yo en el plano irreflexivo (irréflechi)? Aparentemente, si el modo de existencia en el registro de la conciencia irreflexiva es el "hay (il y $a$ ) esta silla" y no el "yo tengo conciencia de esta silla”, no habría lugar para postular un yo en el plano irreflexivo. Sin embargo, el yo acaba por imponerse. Aunque pueda decirse que "al procurar captar el ego por sí mismo y como objeto directo de mi conciencia, recaigo en el nivel irreflejo, y el Ego desaparece junto con el acto reflexivo" (SARTRE, [I936], p.9I), se termina luego por conceder que "el Yo al caer del plano reflejo al plano irreflejo, no se vacía sencillamente: se degrada, pierde su intimidad" (SARTRE, [I936], p.92).
Esta contradicción es importante porque nos conecta con el problema de si la unidad existe per se en una conciencia irreflexiva independiente del ego, o si es la forma en que se entrama la conciencia irreflexiva con el ego luego de su irrupción en el plano reflexivo, lo que otorgaría efectivamente carácter de unidad a ese primer grado espontáneo de conciencia. Como lo veremos, tendremos que decidirnos en favor de esta segunda posibilidad. Tal como la ha mostrado Vassallo, la unidad de la conciencia irreflexiva de la que habla Sartre es, en realidad, un producto secundario de la disyunción reflexiva del acto ${ }^{3}$.

Veamos, pues, cómo esto se dirime si enfocamos el principal aspecto que buscamos examinar, el de la distinción entre la conciencia y el ego. Aunque Sartre pueda sostener que "quizá, efectivamente, la función del Ego no sea tanto teórica como práctica" (SARTRE, [I936], p.IO5), está muy claro que, para él, en la práctica es muy difícil distinguir a la conciencia del Ego: "Todo sucede, pues, como si la conciencia constituyera al Ego como una falsa representación de sí misma; como si la conciencia se hipnotizara con este Ego que ella ha constituido, se absorbiera en él [...]" (SARTRe, [I936], p.Io6, destacado nuestro). Por eso será tan importante el sueño para establecer un deslinde limpio y abrupto entre yo y conciencia.

En resumen, puede decirse que la objeción solapada de Lacan que apuntaría que Sartre transfiere la unidad del ego a la conciencia, quedando a mitad de camino de la distinción teórica que él mismo propone, no es en modo alguno legítima. La dificultad de pensar una conciencia no unitaria tiene que ver con que habitualmente la conciencia se enmascara en la representación de sí que crea en el yo. Y esto es así 
por el modo habitual de articulación entre el par conciencia irreflexiva-reflexiva en el plano de la percepción diurna. Aún para el mismo Lacan, que cuestiona el carácter unitario que Sartre no deja de otorgar a la conciencia, es muy difícil dar cuenta de qué quiere decir una conciencia heterótopa que no tenga centro en ningún sí-mismo. Hasta con el apólogo que introduce tiene dificultades para despejarlo. Nos acercamos así a la idea de que el fenómeno onírico es el único recurso probatorio para demostrar una conciencia desprendida del yo.

Y lo que prueba, entre otras cosas, que Sartre no estaba para nada descaminado (como a veces pareciera querer insinuarlo Lacan) respecto del discernimiento de lo que podría ser una conciencia espontánea no unitaria -o sea, algo parecido a eso que en Lo imaginario él nombra como una conciencia hechizada para la que no existen las posibilidades (SARTRE, I940, p.328), y que ha perdido la noción de realidad ${ }^{4}$ - es precisamente un argumento del mismo Sartre en ese ensayo, que esclarece muy bien el estado de cosas: en el sueño no hay conciencia reflexiva puesto que su aparición provoca inmediatamente el despertar. De esto puede a justo título deducirse que en el sueño estaría excluido el enmascaramiento de la conciencia espontánea en el yo. La diferencia de estructura de la conciencia irreflexiva durante el sueño, cuya participación no es en modo alguno negada, reside en su espontaneidad hechizada. Y si ello es posible es precisamente por la particularidad del fenómeno onírico, que supone una especie de corte abrupto entre la conciencia irreflexiva y la reflexiva. Más abajo retomaremos esta cuestión.

El objetivo de Lacan en estas sesiones del seminario que estamos analizando no parece ser otro que el de captar, en términos prácticos, una conciencia sin yo. Es así que, en su afán de depurar a la conciencia del ego, llega a proponer una definición materialista de la conciencia (LACAN, [1954-55a] I978, p.70), donde la disuelve a tal punto que, sin esa primera referencia al yo, parece tornársenos incaptable, impensable, eso que normalmente entendemos por conciencia. Quizá por ello es que se ve obligado a introducir a los hombres en un segundo momento, como si terminara por confesar que el efecto de disolución que alcanza con el apólogo no llega a hacernos palpable qué es la conciencia.

Podría sostenerse que, para consumar esta separación de la conciencia respecto del ego, sería necesario quitarle el aspecto unitario que Sartre y Lacan le conceden, y que, desde cierta perspectiva, parece ser inseparable de la noción misma de conciencia. (Sartre lo realiza con más voluntad teórica bajo la influencia de Husserl, postulando una conciencia espontánea que se unifica por sí sola $;^{5}$ mientras que Lacan lo hace como a pesar suyo).

La pregunta, entonces, es cómo llegar a producir ese aislamiento en que la conciencia se nos revela como no unitaria $y$ heterótopa, según el término de Lacan. Si la disolución del lazo que une a la conciencia con el yo tiene fundamentalmente el sentido de despojar a la conciencia de su unidad, algo nos lo tiene que hacer palpable. Es lo que parece buscar Lacan con el apólogo que introduce.

El apólogo debe, así pues, permitir captar una conciencia sin ego, “[...] un fenómeno de conciencia que no habrá sido percibido por ningún yo (moi), que no habrá sido reflejado (reflechi) en ninguna experiencia yoica [...]” (LACAN, 
[I954-55a], I978, p.70). ¿Lo consigue? No parece seguro. La historia consiste en hacernos suponer la desaparición de todos los hombres sobre la faz de la tierra, así como de animales y plantas, sin que resten más que cascadas y fuentes, rayos y truenos (LACAN, [I954-55a], I978, p.69). Evidentemente, esto no impide que imágenes en un lago-espejo sigan existiendo; habiendo desaparecido todo ser viviente, una cámara podría grabar esas imágenes. ${ }^{6}$ En un segundo momento, los hombres vuelven. Ellos deberán posiblemente aprender todo nuevamente, "especialmente a leer una imagen" (LACAN, [1954-55a], I978, p.70).

Este apólogo se propone mostrar el aspecto absolutamente contingente de la conciencia al que nos referíamos, limitándosela a la mera existencia de "la superficie de un lago en un mundo inhabitado" (LACAN, [I954-55a], I978: 72). Esto se enmarca en una definición materialista de la conciencia; ésta se produce cada vez que una superficie permita la producción de una imagen, tensión física para nada homogénea a la unidad del yo (LACAN, [I954-55a], I978: 73).

¿Alcanza, entonces, el apólogo para dejar claro el deslinde de la conciencia y el yo? No del todo, al menos. Lo interesante a retener es que, incluso con la ironía del apólogo, se nos muestra que no pareciera haber conciencia pensable sin la captación de una reflexión. Y la pregunta que se impone es ¿quién capta esa reflexión? ¿Por qué el apólogo insistiría, para ilustrar la función de la conciencia, en la importancia de lagos que reflejen imágenes, si no fuera por esos hombres que vuelven al mundo y tienen que ver la grabación de las imágenes? Esta cuestión ha sido muy oportunamente señalada a Lacan por Jean-Bertrand
Pontalis en su intervención en el curso de la quinta sesión del seminario:

Usted olvidaba sólo una cosa, es que era necesario que los hombres vuelvan para captar la relación entre el reflejo y la cosa reflejada. Dicho de otro modo, si se considera al objeto en sí mismo y a la película grabada por la cámara, eso no es nada más que un objeto. No es un testigo, no es nada. (LACAN, [1954-55a] I978, p. 85 , traducción nuestra).

El carácter un poco forzado de la historia es tramposo porque nos hace suponer que no existe aquello mismo cuya existencia requiere, o sea, la presencia de hombres que retornen al mundo para ser testigos de la reflexión de esa imagen; ¿y en qué medida es posible pensar la categoría "hombres" sin la función psíquica del Moi? Es cierto que Lacan, en pos de respaldar el planteo que sostiene, insiste en que no es la función imaginaria de esos hombres lo que se tornaría necesaria para esa captación, sino tan sólo el registro simbólico del Je, a cuyo lado pareciera querer inclinar el fenómeno de la conciencia. Sin embargo, tampoco parece nada simple y justificado hacer una separación tan tajante entre Je y Moi.

En síntesis, con el apólogo Lacan busca decir que la conciencia está restringida al simple hecho mismo de la producción de la imagen, pero no se termina de entender lo que está en juego (y por eso necesita volver a introducir a los hombres en el mundo) si no se piensa que el sueño es ese producto psíquico paradigmático que vemos como una imagen proyectada: "el sueño se parece mucho a una lectura en el espejo" (LACAN, [I954-55a] I978, p.84). En el fenómeno onírico hay una captación instantánea e inmediata de la 
imagen por la conciencia sin que sea necesario que supongamos una función de la mismidad yoica que la soporte. La definición de la conciencia como beterótopa sólo se justifica por una espontaneidad en la captación de la imagen que no se apoya en ningún sí mismo.

De acuerdo con esto, podemos decir que la conciencia sin yo que el apólogo nos propone sería algo impensable si no existiera un fenómeno fundamental que todos hemos experimentado, el del sueño, punto argumental de apoyo en Lacan para mostrar qué quiere decir una conciencia sin yo, o sea una conciencia heterótopa, que no permite la deducción de un sujeto.

"Un sueño es consciente"(LACAN, [1954-55a], I978, p.84, destacado nuestro): es tan incuestionable que somos conscientes respecto del sueño cuando soñamos como sería inadmisible adjudicar al sueño un sujeto que se sepa consciente de sí. O sea, un sujeto autoconsciente que se captara como correlato (noético) del sueño. El yo está disuelto, diseminado, y no por ello el sueño es menos consciente. Se trata de un fenómeno clave, una pieza argumental crucial en Lacan para mostrar una escisión posible entre yo y conciencia.

Retomaremos más adelante estas cuestiones con mayor detalle desde otra perspectiva, cuando examinemos los argumentos de Sartre sobre el lugar del cogito en el sueño.

\section{El cogito cartesiano: EL SUEÑO Y LA LOCURA}

Antes de avanzar, valdría la pena indicar sucintamente la posición discrepante que mantiene el cogito respecto del sueño y la locura, con miras a poder dilucidar mejor la relación entre cogito y sueño.
Los planteos de Michel Foucault en Historia de la locura en la época clásica que suscitaron una conocida discusión con Jacques Derrida son los que mejor permiten esbozar el problema ${ }^{7}$. Su tesis sostiene que hay un desequilibrio fundamental en la economía de la duda: entre locura, por un lado; y sueño y error, por otro (Foucault, 1972). Aunque no haya en el sueño, como lo veremos más adelante, una captación posible del cogito, aunque el sueño no sea apto para el ejercicio de la duda, la experiencia onírica no es ajena a la meditación, como sí lo es la locura. Esta es la distinción que le objeta Derrida, buscando poner en el mismo rango todo lo proveniente de lo sensible que el cogito rechaza. Nosotros acordamos con el tratamiento diferencial que debe dársele al sueño y a la locura, siempre y cuando tomemos en cuenta algo que aparece soslayado por Foucault, y que la objeción de Derrida permite vislumbrar: la meditación del cogito para llegar a ser tal debe depurarse del cuerpo de la experiencia onírica.

De acuerdo con Foucault, la locura está excluida del cogito: "Yo (moi) que pienso, yo (je) no puedo estar loco [...] es una imposibilidad de estar loco, esencial [...] al sujeto que piensa". En cambio, sí es posible suponer "que se sueña e identificarse al sujeto que sueña para encontrar «alguna razón de dudar»" (Foucault, I972, p.68). "Si el hombre puede siempre estar loco, el pensamiento, como ejercicio de la soberanía de un sujeto que se pone en el deber de percibir lo verdadero, no puede ser insensato"(Foucault, I972, p.70). Si con esta afirmación, se trata para Foucault de sellar la exclusión de la locura por parte del cogito, nosotros la inclinaremos hacia el problema que aquí nos interesa examinar: la distinción entre el cogito y el pensamien- 
to del sueño. El sueño es permeable a la meditación, el soñar constituye una pieza clave para avanzar en su ejercicio, pero es a la vez fundamental que la meditación se vaya liberando de todas las impurezas del soñar para arribar al cogito como pensamiento actual, incorpóreo. El cogito debe depurarse de las inactualidades del cuerpo (KuRI, I996), y, entre ellas, la que surge del sometimiento al ejercicio del soñar es primordial. Aunque en mi soberanía de sujeto meditante participe del ejercicio del soñar ${ }^{8}$, es preciso, como condición para el sostenimiento de la meditación, que, como sujeto auto-consciente, esté seguro de que no sueño.

Retomando los términos que Foucault aplicaba a la locura en la reciente cita, podemos afirmar que es necesario que el hombre que medita pueda hacer como que sueña en el ejercicio de la duda; pero, al mismo tiempo, es fundamental que, en un segundo movimiento, el pensamiento se depure del hombre. El hombre que medita debe llegar a ser puro pensamiento en su coincidencia actual - y narcisista- consigo mismo; y, para ser tal, el pensamiento tiene que dejar atrás la posibilidad de estar soñando; es decir, debe estar seguro de que no sueña.

Integrar el cuerpo al cogito supone otro movimiento filosófico, el que produce Sartre al tomar en cuenta el "modo opaco con que el cuerpo turba a la conciencia” (KuRI, I996, p.I08), lo que permite entender porqué el cuerpo sartreano puede ser presentado como "la irrupción de la contingencia en el cogito" (KurI, I996, p.I09). En contraposición a los fundamentos que Descartes busca otorgar al pensamiento meditante, la contingencia sería todo lo que el cogito cartesiano debe hacer a un lado para alcanzar la pureza de la meditación: el cuerpo en lo que tiene de inactual, la conciencia en lo que tiene de soñante, el pensamiento en lo que arrastra de hombre.

DISTINCIONES ENTRE LA VIDA ONÍRICA Y LA REALIDAD DIURNA DESDE EL PUNTO DE VISTA esCópico. Hacia una mirada desprendida de la vista, escamoteada por la función de la conciencia.

\section{LA MANCHA FASCINANTE DE LOS OCELOS 9}

La mancha es lo que viene a inscribir la falta de una manera que permite cuestionar un espacio diferente al de la estética geometral del mundo, centrado en un sujeto al que todo remite. Ese sujeto, ubicado desde determinado lugar, que puede ser equiparado a un punto espacial, es el que se representa, se arma un mundo. No se trata de otra cosa que de "esa estesia representativa donde el individuo se encuentra y se apoya, identificado a sí mismo en la relación narcisista en que se afirma como individuo" (LACAN, I 966-67, p.520). Ahora nos ocuparemos de la mancha para interrogar, a partir de su especificidad en el ámbito escópico, un modo del espacio desprendido de la función de la conciencia.

En la estética geometral todo se juega en la dialéctica entre apariencia y cosa en sí, reemplazada en Lacan por la esquizia de la apariencia y la mirada. Veamos las implicancias de esta sustitución. Siguiendo los desarrollos de Roger Caillois, Lacan interroga la función de mancha de los ocelos: ¿son éstos fascinantes por su parecido con el ojo o es más bien la semejanza con los ocelos lo que hace atractivo al ojo? 
Si retomamos la pregunta que Lacan se formula, la diferencia de acento en cuestión es propicia para mostrar que el ojo no coincide necesariamente con la mirada, puesto que algo puede mirar sin desempeñar el papel de órgano de la visión ${ }^{10}$. La fascinación no surge de la semejanza realista con dicho órgano, becho para ver según la perspectiva adaptativa y finalista que tanto Caillois como Lacan cuestionan, sino porque hay algo que mira independientemente y más allá de la función de la vista (delimitada por un mundo imaginario formado por líneas geometrales entrecruzadas, aquellasque un no vidente podría espacialmente constituir a pesar de su ceguera).

El efecto de fascinación de los ocelos es redoblado por su semejanza con el órgano de la vista, aunque esta eventualidad accidental no debe extraviarnos respecto de lo crucial de la cuestión: los ocelos no miran por asemejarse al ojo, sino porque la función de la mirada no se encuentra supeditada a ningún órgano particular. Ella está, antes de que pueda siquiera pensarse en una similitud respecto del ojo, representa$\mathrm{da}^{11}$ por la función de la mancha que opaca y desfigura la constitución geometral del mundo.

¿Cuál es el alcance de identificar el problema de la mirada con la función de la mancha? Se trata de trasladarla a otra dimensión que la del ojo como punto geométrico. Para dar cuenta de su función es preciso correrse de la vertiente que postularía al sujeto como un punto desde el cual se construye el mundo visto, viéndose a sí mismo ver en ese mismo movimiento, y acaparando así al mundo en la reciprocidad narcisista del propio yo.

Para captar la función de la mirada hay que ir más allá de la estesia representati- va del sí mismo. Es a esta concepción del mundo escópico que Lacan contrapone la "función de la mancha y la mirada", destacando que ella escapa "a la captación de esa forma de visión que se satisface de sí misma imaginándose como conciencia" (LACAN, [I964 a] I973, p.87). La vuelta de la conciencia sobre sí misma, viéndose verse, representa un escamoteo de la función de la mirada. Ello puede observarse contrastando el lugar del sujeto en el mundo imaginario desplegado en el sueño con aquel que ocupa durante la vigilia. El narcisismo es el punto de anclaje de la función de desconocimiento que prevalece y que alcanza su apogeo en la plenitud fantasmática de la contemplación, elidiendo precisamente la función de la mirada: lo inquietante en el campo escópico.

\section{LA otra escena COMO ALTERIDAD ESCÓPICA DEL NARCISISMO}

El sueño pareciera enfrentarnos con la pureza de un mundo visual en que no opera una dimensión geometral ${ }^{12}$, o en que la misma está reducida a un mínimo. Aunque el topológico, ese "espacio englobante” (Merleau-Ponty, I964, p.266) según la caracterización de Merleau-Ponty, no pueda ser estrictamente homologado con el espacio del mundo onírico, el primero nos orienta sobre muchas cuestiones para el esclarecimiento del segundo.

Si seguimos a Merleau-Ponty, las cosas no están espacialmente en el mundo en tres dimensiones; ellas están emplazadas en un mundo en que no hay dimensiones, en el que, si las hubiera, habría que hablar mejor de una sola dimensión, como el fenomenólogo lo propone refiriéndose a ese singular espacio al que nos permite acceder la pintura. De acuerdo con Lacan, 
el mundo del sueño no tiene horizonte (LACAN, I964b, p.II2), constatación que permite acercarnos a una apreciación de Merleau-Ponty muy valiosa para situar lo onírico: a la noción de dimensión hay que contraponerle la de profundidad; las cosas están superpuestas, como por fuera, sacadas las unas de las otras.

¿De qué manera, enmascarándose a sí misma, la percepción se transforma en euclidiana? (Merleau-Ponty, I964, p.263). A esta pregunta que el fenomenólogo se formula, podríamos responder lo siguiente: hay algo esencial, inherente a la percepción diurna, que supone dicho enmascaramiento, encubrimiento de la conciencia por el yo, al que más arriba nos referimos. ${ }^{13}$ Lo que da ese modelado euclidiano a la percepción de la vigilia, imponiendo un modo de conocimiento del mundo, no es otra cosa que el narcisismo especular.

La diferencia fundamental del mundo de vigilia con el mundo onírico resulta de que en este último no hay propiamente una escena montada sobre el mundo: el sueño nos enfrenta con la realidad escópica del mundo a secas, sin intermediario; con la Otra escena (anderer Schauplatz) como tal. Interpretamos aquí el sentido de la Otra escena como alteridad escópica del narcisismo, aquello que está destinado a mantenerse oculto en la realidad fantasmática diurna. Lo que el narcisismo vela es la realidad topológica de la Otra escena.

La sustracción del objeto a posibilita el montaje de una escena en el mundo. Al objeto sustraído de la visión le corresponde un lugar desde el cual el sujeto se ubicaría como punto de mira, soporte de la estesia representativa donde puede verse constituido como yo narcisista. Se trata de un sujeto degradado a funcionar como punto geometral, es decir, al nivel de eso que
Lacan especifica como sujeto cartesiano. El conocimiento del mundo que a raíz de ello se produce tiene esa misma estructura narcisista; no se trata de otra cosa que de la función misma de lo imaginario en el hombre, caracterizada tempranamente por Lacan como función de desconocimiento (LACAN, [I949] I970, p.98). La presencia inquietante del objeto debe estar anulada para que se mantenga la ilusión narcisista del reconocimiento en la propia imagen.

Si consideramos ahora la asimilación establecida por Lacan entre sujeto y mirada a propósito del clásico sueño del hombre de los lobos (LACAN, [I964a] I973), podemos esbozar algunas otras precisiones. El acceso a la escena primaria que el sueño-fantasma nos otorga, hace posible pensar en una suerte de continuidad con laconfiguración especular de los sueños en general.

En general, los sueños ponen en juego una especie de sobreabundancia de lo visual. En ellos no pareciera operar la sustracción en el campo escópico que permitiría situar esa forma degradadade sujeto: el punto geometral del ojo. Que el sujeto coincida con la mirada quiere decir que hay un eclipse entre el sujeto y su mundo visual, que no hay distancia ni horizonte, en términos semióticos, que no hay referentes ni signos icónicos, sino puros signos plásticos. ${ }^{14}$ En el sueño, el sujeto quedaría identificado con eso que se ve.

Que el sujeto sea la mirada, como lo sostiene Lacan respecto del sueño del hombre de los lobos ¿no es, entonces, una formulación en cierto punto válida mayormente para la escenificación visual de todo sueño?

Allí podemos encontrar las indicaciones para una distancia insalvable entre la 
estructura especular del sueño y aquella de la vida de vigilia. El análisis del sueño de la inyección de Irma había llevado a Lacan a inferir una disolución espectral del yo, típica de los fenómenos oníricos. El yo aparece diseminado por todos lados, el sueño no es visto desde una perspectiva geometral. En otro términos, el sujeto es la mirada, es la mancha de los signos plásticos, no se presta al ejercicio pensante del cogito; no hay lugar para ese tipo de pensamiento, para la meditación, puesto que el yo está sumido en el cuerpo, pulverizado por la acción simbólico-imaginaria (la Darstellung) del soñar (LACAN [I95455a] I978).

Estos desarrollos prefiguran la afirmación del seminario Los cuatro conceptos... en que se sostiene que el mundo es omnivoyeur pero no exhibicionista, puesto que "no provoca nuestra mirada"(LACAN, [I964a] I973, p.88). Intentemos desglosar el contrapunto en juego en esta frase: si el sueño se vuelve exhibicionista es porque no está en él velado el carácter omnivoyeur del mundo, como sí es el caso para la vida de vigilia, gracias a esa modalidad fantasmática de sostén acoplada al desconocimiento del narcisismo especular.

En el sueño, la mirada del mundo llama a nuestra mirada, pero el efecto que produce se limita a esa mirada empastada en la proliferación de imágenes, mirada no supeditada a un ojo geometral, que no mantiene ninguna distancia perspectiva respecto de lo que ve.

De acuerdo con estas consideraciones, podemos decir que es el carácter voyeurista del mundo el que ocasiona su exhibicionismo posible durante el sueño. En la vida despierta la correspondencia está fracturada por la pantalla que la vela, cuando ésta tambalea o deja de operar, provoca una cierta extrañeza en nuestro mundo de vigilia que podría asociarse con el sentimiento de lo Unheimliche.

\section{El “ESO MUESTRA” (ça montre) DEL SUEÑO: EXHIBICIONISMO ESTRUCTURAL DEL MUNDO. La garantía de la vigilia y la falta de garantía en el sueño}

En cuanto a las especificidades escénicas del sueño, la ausencia de un punto geometral desde el cual se miraría eso que el sueño muestra queda por demás evidenciada en una de las características de lo especular en la vida onírica puestas de relieve en el Seminario 11: "la ausencia de horizonte" (LACAN, [I964a] I973, p.88). La posición del sujeto en el mundo onírico esla de quien no ve, por lo queel soñante no podrá captarse en el sueño tal como lo hace en el cogito como pensamiento (LACAN, [1964a] I973).

La captación del cogito es profundamente escópica en el sentido de la vida diurna, podríamos decir, con los engaños y ocultamientos que le son inherentes, los que son propios del narcisismo. Es necesario un cuerpo unificado para la meditación cartesiana: el cuerpo unificado es el que podría acoplarse al pensamiento de la duda, el cuerpo dócil del yo es el que se presta a la meditación. En ese sentido es que creemos que la narcisista es la única dimensión del cuerpo que escapa a la fractura, propuesta por Kuri, entre sujeto meditante y cuerpo (KuRI, I996, p.I04). En cambio, es el cuerpo del afecto, no alojado cómodamente en el yo imaginario, el que perturba la meditación.

El cuerpo narcisista conlleva la ficción de una coincidencia consigo mismo, lo que permite deducir una complementariedad, 
entre el propio cuerpo como uno y el acto meditativo, que reside en la contemporaneidad del ejercicio de pensarse siendo; o, en el acto de verse viéndose, si colocamos simplemente el acento en el campo escópico que aquí nos ocupa. (Es cierto que esa coincidencia se desarma, mostrándonos que la certeza sólo puede encontrársela en la enunciación, pero ése ya es otro asunto que supone tomar en cuenta la ganancia discursiva que extrae Lacan del cogito cartesiano al aproximarlo al sujeto del inconsciente, cogito freudiano). ${ }^{15}$

El desencuentro de lo corporal con el acto meditativo requiere de otro cuerpo como referencia, el cuerpo pulsional, allí ubicaríamos ese "[...] cuerpo que no ve Foucault [...] un sistema de inactualidad del cuerpo" (Kuri, I996, p.I06). ${ }^{16}$ "Pues si el sueño "hace la actualidad del sujeto no menos dudosa que la locura» [...] no consigue eliminar la figura del cuerpo que molesta". Si el camino de la meditación cartesiana se dirige a constituir un "cuerpo sin movimiento" (KURI, I996, p.Io8) es porque lo necesita para apartar lo fastidioso de ese cuerpo atravesado por la experiencia onírica, recorrido inicialmente en el ejercicio meditativo.

La ductilidad onírica para la meditación es tal porque el sujeto mediante tieneuna garantía del lado en el cual está, garantía que le permite resolver fácilmente la inquietud de la pregunta: ¿estoy despierto o soñando? Sabe que está despierto, se lo asegura la "identidad enajenante" (LACAN, [1949], I97I: 96) que narcisísticamente lo sostiene, estructura de engaño que se asienta en una "identificación objetivante" ([I948], I970: II I). Si estuviera soñando la meditación no sería posible y, por tanto, no habría ni siquiera marco para plantear la pregunta. Para ello se requiere, como ahora lo veremos, el desdoblamiento entre el yo y su alter ego que no opera en el sueño.

Estas cuestiones pueden cernirse a partir del análisis que Lacan efectúa de Chuangtzú y su sueño de ser una mariposa. Más que encontrar la "falta de garantía" en la distinción realidad / sueño (HAImovich, 20I I), leemos allí la diferencia fundamental de estructura escópica en ambos casos, lo que determina que no haya tal falta de garantía. La diferencia fundamental reside en que, al estar despiertos, nunca podríamos creer que estamos soñando, aunque podamos colocarnos en el lugar de soñante durante el ejercicio de la meditación cartesiana. La inversa sí es posible: soñando podemos creer que estamos despiertos, punto de apoyo en Descartes para extender la duda a lo que transmiten los sentidos. (Veremos en lo que sigue cómo esta contraposición se aclara con los análisis de Sartre a los que nos referiremos).

El hecho de que Chuang-tzú sueñe que es una mariposa significa que "ve a la mariposa en su realidad de mirada". "En el sueño no es mariposa para nadie. Es cuando está despierto que es Chuang-tzú para los otros”, y que puede, por tanto, "preguntarse si no es la mariposa que sueña que es Chuang-tzú” (LACAN, [I964a] I973, p.88). Se percibe bien cómo, estando despierto, puede pensarse a partir del cogito, lo que no supone arribar a ninguna identidad acabada, sino más bien a la diferencia consigo mismo constitutiva del yo especular de la vigilia, que le posibilita preguntarse si no podría en realidad ser otro. La inversa no es posible: "cuando es la mariposa, no le viene la idea de preguntarse si, cuando es Chuang-tzú despierto, no es la mariposa que está soñando ser" (LACAN, [I964a] I973, p.88). Se entien- 
de: porque en el sueño el sujeto no puede captarse como lo hace en el cogito como pensamiento.

\section{LA CONCIENCIA IMAGINANTE DEL SUEÑO: NI PERCEPCIÓN NI CONCIENCIA REFLEXIVA}

La heterogeneidad de estructura entre mundo onírico y vigilia puede ser aún mejor esclarecida si nos referimos a los abordajes que sobre el sueño efectúa Sartre en su ensayo L'imaginaire. Luego de haber examinado lo propio de la conciencia imaginante en sus diferentes manifestaciones,el autor se ve llevado a preguntarse, en el último capítulo del libro, si para el único caso del sueño no podría ser válido algo que contradiría la tesis fundamental allí desplegada; la que sostiene que la imaginante y la perceptiva son dos tipos diferentes de conciencia que se excluyen la una a la otra (SARTRE, I940: 3 IO). Es decir, Sartre se pregunta si para el único caso del sueño no podría ocurrir que la imagen se dé como una percepción. La respuesta será evidentemente negativa: en el sueño no se trata de conciencia perceptiva sino de conciencia imaginante.

Sin embargo, el solo hecho de que este caso haga posible, al menos, la formulación de la pregunta, nos permite situar en perspectiva la especificidad de la imagen en el sueño respecto de la problemática de la percepción en la realidad diurna. "Es posible que en el sueño me imagine que percibo; pero lo que es cierto es que, cuando estoy despierto, no puedo dudar de que percibo" (SARTRE, I 940, p.3 I I, traducción nuestra). La ficción de fingir que sueño es absurda. "El sueño es la realización perfecta de un imaginario cerrado (clos)", del que de ningún modo se puede salir; es imposible tomar un "punto de vista exterior”(SARTRE, I940, p.320), puesto que en el sueño la "conciencia es arrastrada por su propia caída [...]" (SARTRE, I940, p.326).

No es que la conciencia no tética de imaginar deje de captarse como espontaneidad, sino que ella se capta a sí misma como espontaneidad hechizada (envoûtée). Es lo que da al sueño su matiz propio de fatalidad. Los acontecimientos se dan como no pudiendo no suceder, en correlación con una conciencia que no puede impedirse imaginarlos. (SARTRE, I940, p.328, traducción nuestra)

De allí que Sartre pueda concluir con firmeza que "no hay en un mundo imaginario, sueño de posibilidades" (SARTre, I940, p.328). La posición de existencia del soñante y del hombre despierto no coinciden ${ }^{17}$, puesto que las conciencias no téticas de sueño y vigilia difieren en la manera de poner (poser) sus objetos, y no hay reflexión posible dentro de la conciencia imaginante del sueño: "toda aparición de la conciencia reflexiva en el sueño corresponde a un despertar momentáneo" (SARTRE, I940, p.3 I2).

¿Nos fuerza el análisis de Sartre a deducir que lo onírico como experiencia está más excluido del cogito cartesiano que la locura? Depende de la perspectiva que tomemos. Para el filósofo, lo que sucede en el sueño debe distinguirse de lo que le ocurre al esquizofrénico, quien mantiene, a diferencia del soñante, la posibilidad de captarse actuando (SARTRE, I940, p.325). El punto de enfoque, completamente diferente al de Foucault, nos transmite aquí otra enseñanza valiosa: si el sueño está en este caso excluido del cogito es porque supone otro cuerpo distinto al que prima en 
la experiencia perceptual del pensamiento diurno (apto al trabajo de la conciencia reflexiva).

Puesto que se trata en Sartre de problematizar el sueño y la esquizofrenia como experiencias divergentes en función de los modos de la conciencia implicados en cada caso, el resultado no podría dejar de ser distinto al de Foucault, que toma por eje sueño y locura en relación con su docilidad o no respecto del ejercicio de la meditación cartesiana. En Sartre, es la relación percepción-cuerpo la que impera: no hay cogito sin percepción molesta del cuerpo (el cogito parece estar excluido de entrada en su consideración del sueño, puesto que éste no admite ni percepción ni conciencia reflexiva, la que produce inmediatamente el despertar); en Foucault, podemos leer -introduciendo el problema del cuerpo que éste soslaya- que lo fundamental radica en la retención del movimiento del cogito, en que el pensamiento puro de la meditación se va liberando de lo que tiene de hombre percipiente (e imaginante). La locura, en cambio, no se presta a este ejercicio porque está de entrada excluida del discurrir meditante del cogito.

\section{Conclusiones}

La creencia en una supuesta reciprocidad entre el punto en que se origina la acción de ver —atada al pensamiento del cogito y de la conciencia- y lo visto, es parte de la ilusión del imaginario narcisista. La constitución especular narcisista, fundada en la ilusión de reciprocidad entre el vidente y su imagen, desconoce elcuerpo abierto a la alteridad del mundo y las cosas que el fenómeno de la conciencia desligado del narcisismo especular permi- te vislumbrar. Para captarlo, la experiencia onírica es fundamental, pudimos mostrarlo examinando los análisis efectuados por Sartre y Lacan.

Analizando las consecuencias del desprendimiento entre conciencia y yo buscamos mostrar otro acceso a la experiencia perceptual de la conciencia, atada habitualmente a la operatoria del narcisismo especular. El sueño permite despejar mejor que ninguna otra formación psíquica qué implicancias tiene una conciencia no enmascarada por el ego; punto de apoyo argumental para mostrar qué quiere decir una conciencia sin yo, heterótopa, esto es, que no permite deducir un sujeto.

Pudimos dar cuenta de por qué la contracara de la disolución yoica en el sueño es la meditación cartesiana en que se funda el cogito. Tomando como apoyatura el análisis de Foucault buscamos mostrar que si el sueño se presta al ejercicio de la duda metódica (a diferencia de la locura), es a condición de que la meditación vaya liberándose progresivamente de las impurezas del soñar para arribar al cogito como pensamiento actual, incorpóreo. Este segundo movimiento, en que el pensamiento se depura de su resabio de hombre soñante, es fundamental porque nos muestra que el sujeto meditante debe llegar a ser puro pensamiento en su coincidencia narcisísticamente actual consigo mismo. El cogito cartesiano debe hacer a un lado la contingencia para alcanzar la pureza de la meditación: debe liberarse de la inactualidad del cuerpo, y de lo soñante que la conciencia acarrea (para que ésta pueda culminar por afirmarse, enmascarándose en un "Yo pienso").

Habría que hacer responsable al mundo escópico de la vigilia del enmascaramiento por el cual la percepción se vuel- 
ve euclidiana. Ese condicionamiento que hace posible el conocimiento del mundo es adscribible a la estructura misma del narcisismo especular. En contraste con ello, la sobreabundancia visual propia de los sueños, nos muestra una no sustracción en el campo escópico, la que es correlativa de la instauración del sujeto cartesiano como ojo-punto geometral, forma degradada de sujeto. Que en el sueño el sujeto coincida con la mirada quiere decir que se produce una especie de eclipse entre el sujeto y su mundo visual, pues no hay horizonte posible ni distancia entre ellos.

Para finalizar, acentuamos que en el sueño no hay ningún sujeto uno; el sujeto geometral cartesiano, que en la vida diurna se apuntala en la constitución narcisista del yo, está diseminado en las imágenes del sueño, multiplicado y desperdigado entre ellas. Ello nos lleva a afirmar quela captación del cogito es profundamente escópica en el sentido de la vida diurna, con los engaños y ocultamientos, propios del narcisismo, que le son inherentes. Es necesario un cuerpo unificado para la meditación cartesiana; es el cuerpo dócil del yo el que podría acoplarse al pensamiento de la duda, prestándose al ejercicio meditante. El cuerpo narcisista conlleva la ficción de una coincidencia consigo mismo, de lo que se deduce una complementariedad entre el propio cuerpo como uno y el acto meditativo. Ella instaura la ficticia contemporaneidad —que el inconsciente no hace más que desmentir incesantemente- en el ejercicio del pensarse siendo, o en la acción del verse viéndose.

\section{Notas AMPLIATORIAS}

$1 \mathrm{El}$ andamiaje por el cual la réplica en el interior de lo que está en el exterior, asociado a la idea de que el avance sobre el mundo consiste en que nos lo representamos, ha tenido una prevalencia en la historia que tomó la forma de un discurso, “[...] aquel de una representación hecha para sostener esta idea de la representación. Es en la representación que da tal ventaja a la representación que consiste, en fin de cuentas, el nudo secreto de lo que se llama idealismo" (LACAN, [1968-69] 2006, p.282). El hecho de que la concepción del sujeto del idealismo guarde cierto grano de verdad - Lacan habla de un sujeto de la representación ubicado en el centro de un esquema al que caracteriza como berkelyano- - se refiere a que en la resolución idealista de Berkeley hay algo de verdad, aunque no tenga razón (LACAN, [1968-69] 2006, p. 286).

2 "Es inútil «recurrir a un poder sintético del yo» porque la conciencia «irréflechie», por así decir, se unifica sola" (VAssallo, 20I3, p.56).

3 "El deslizamiento constante entre «irréflechie» y «réflechie» desafía el clivaje entre conciencia y yo, pero no lo sutura. En cuanto la conciencia se vuelve sobre sí misma, deja de ser «irréflechie», pero al segundo siguiente vuelve a serlo por efecto del estatuto de "producto» del yo" (VAssallo, 20I3, p.57). "Esa unión previa es «creada" por el Yo, no es un dato "de hecho", ya que la conciencia irreflexiva $[. .$.$] no$ forma parte de las entidades «de hecho» sino «de derecho». Se explica así que «la unión previa» coexista siempre con su contrario, o sea, una ruptura. Es la noción de acto la que hace posible esta contradicción." (VASSALlo, 20I3, p.6I)

4 "Lo que caracteriza a la conciencia que sueña es que ha perdido la noción misma de realidad." (SARTRE, I940, p.320) 
5 "Marcado por La conciencia del tiempo inmanente de Husserl, Sartre insiste en que una actividad propia afecta a la conciencia impersonal por la cual se ligan las representaciones antes de que el yo haga su aparición." (VASSAllo, 20I3, p.56)

6 La importancia de la cámara creemos que se limita a mostrar el anclaje en el mundo simbólico del que el hombre es parte, y que ha permitido construirla; la inserción simbólica del Je en la estructura sería, así pues, una condición para el fenómeno de conciencia.

7 Apoyado en la idea de que "Toda significación, toda «idea» de origen sensible queda $e x$ cluida del dominio de la verdad, bajo el mismo título que la locura." ( I989, p.7 I) Derrida cuestiona los planteos de Foucault en su conferencia "Cogito e historia de la locura"; y éste le responde en un apéndice agregado a la ediciones posteriores de Historia de la locura en la época clásica, "Mi cuerpo, ese papel, ese fuego." (I990)

8 "Esta experiencia posible no sólo es un tema para la meditación: se produce real y actualmente en la meditación, según la serie siguiente: pensar en el sueño, recordar el sueño, tratar de preparar el sueño y la vigilia, no saber ya si se sueña o no, y hacer voluntariamente como si se soñara." (FouCAULT, I990, p.347)

9 El Diccionario de la Real Academia Española remite etimológicamente "ocelo" al latín ocellus que equivaldría a "ojito". Se explicitan dos definiciones diferentes para el término, lo que guarda interés para lo que nos ocupa: en un caso se trata efectivamente del órgano de la vista en algunos insectos, mientras que en el otro, simplemente de una mancha que se presenta en ciertos insectos (que se asemeja a un ojo): "1. $\mathrm{m}$. Zool. Cada ojo simple de los que forman un ojo compuesto de los artrópodos. 2. m. Zool. Mancha redonda y bicolor en las alas de algu- nos insectos o en las plumas de ciertas aves". (Recuperado de http://dle.rae.es/?id=QrPbr2g)

10 En relación a los ocelos "se trata de comprender si impresionan - es un hecho que tiene ese efecto sobre el predador o la presunta víctima que vienen a mirarlos- si impresionan por su semejanza con los ojos, o si, al contrario, los ojos no son fascinantes más que por su relación con la forma de los ocelos. Dicho de otra manera, ¿no debemos a este propósito distinguir la función del ojo de aquella de la mirada?" (LACAN, [I964A] I973, p.86)

11 Acentuamos la carga paradójica de ese representado, que aproximamos aquí más a la noción de Darstellung que a la de Vorstellungsrepräsentanz.

12 Podríamos aducir aquí lo que Ritvo sostiene para el imaginario fantasmático, que "no admite no sólo las coordenadas euclidianas sino tampoco geometría alguna.” (Ritvo, 2009a, p.I44)

13 El enmascaramiento de la percepción por sí misma no podría limitarse a la perspectiva como hecho de cultura renacentista, aunque esto no quita que ella suponga, como el filósofo lo sugiere, una importante influencia que actuaría en contra del reconocimiento de que "la percepción misma es polimorfa." (MERLEAUPONTY, I964, p.263)

14 La terminología semiótica también sirve de soporte para precisar un poco más la cuestión. Es como si no hubiera, en la Otra escena onírica, signos icónicos que permitan anclajes referenciales, dejando completamente inmerso al soñante en ese mundo de signos plásticos. El sueño cuestiona incesantemente el estatuto estable que posee la imagen especular. (Ritvo, 2009b, p.II4)

15 Esa ganancia discursiva es la que permite afirmar que "el cogito no funda la concien- 
cia, [sino que] revela la división del sujeto”. (Lemosof, 201 5, p.92)

16 Kuri sostiene que Foucault es presa de una "desconsideración del grado de inactualidad inberente a lo corporal aún fuera de la locura." (KURI, I996, p.IO8)

17 Si hay algo en la vida diurna que se aproxima de la conciencia del sueño, es precisamente aquello que Sartre llamó "conciencia de la emoción”. En su temprano ensayo Esquisse d'une théorie des émotions, todas sus descripciones apuntan a despejar el carácter cautivo de una conciencia que no deja de ser espontaneidad, lo que no significa, por supuesto, que la conciencia "sea libre de negar algo en el momento mismo en que pondría ese algo" (SARTRE, [I938] I995, pp.IOI-IO2). De esta relación entre el mundo del sueño y el mundo de la emoción, sólo retenemos un carácter fundamental de este último que, en tanto "intuición de lo absoluto" (SARTRE, [1938] I995, p.I05), puede ser trasladado a la particular estructura escópica del sueño (por estar también corrida de los actos de percepción ordinaria): "Así, a través de la emoción, una cualidad aplastante y definitiva de la cosa nos aparece" (SARTRE, [I938], I995, p.I04, destacado nu estro).

\section{REFERENCIAS BIBLIOGRÁFICAS}

Derrida, J. (I989). "Cogito e historia de la locura”, en La escritura y la diferencia. Barcelona, Anthopos.

Foucault, M. (I972). "Le grand renfermement", en Histoire de la folie à l'âge classique. Paris, Tel Gallimard.

( I990). “Apéndice: Mi cuerpo ese papel, es fuego", en Historia de la locu- ra enla época clásica Vol II. Buenos Aires, Fondo de Cultura Económica.

Haimovich, E.; Kreszes, D. (20I I). Fantasía: metapsicología y clínica. Rosario, Homo Sapiens Ediciones.

Kuri, C. (I996). "El cuerpo de la meditación”, en Redes de la letra 6, 99-I09.

LACAN, J. [I948] (I97I). "L'agressivité en psychanalyse”, en Écrits I. Paris, Seuil Point Essais.

[I949]. (I999). "Le stade du miroir comme formateur de la fonction du Je", en Écrits I. Paris, Seuil Point Essais. [1954-55a] (1978). Le moi dans la théorie de Freud et dans la technique de la psychanalyse. Paris, Seuil Points essais.

[I954-55b] (I978). Le moi dans la théorie de Freud et dans la technique de la psychanalyse.URLstaferla.free.fr/S2/ S2.htm, página web http://staferla.free.fr [I960] (I97I). "Subversion du sujet et dialectique du désir dans l'inconscient freudien", en Écrits 2.Paris. Seuil Points.

ris, Seuil.

[1962-63] (2004). L'angoisse. Pa[1964a] (I973). Les quatre concepts fondamentaux de la psychanalyse. Paris,Seuil Points.

(I964b). Fondements. URLstaferla.free.fr/SII/SII.htm, página web: http:// staferla.free.fr

(1966-67) La logique du fantasme. URLhttp://staferla.free.fr/S I $4 / S_{I} 4$. htm, página web: http://staferla.free.fr [1968-69] (2006). D’un Autre à l'autre. Paris: Seuil.

Le Gaufey, G. (I997). Le lasso spéculaire: Une étude traversière de l'unité imaginaire. Paris: EPEL. 
Lemosof, A. (2015). "El objeto del psicoanálisis", en Lacaniana II. Buenos Aires, Paidós.

Merleau-Ponty, M. (I964). Le visible et l'invisible. Paris, Gallimard.

Ritvo, J. (2009 a). "La bolsa del cuerpo y los dos imaginarios", en Figuras de la feminidad. Buenos Aires, Letra Viva. (2009 b). "El estatuto de la imagen en Freud: Rücksicht auf Darstellbarkeit”, en Figuras de la feminidad. Buenos Aires: Letra Viva.

SARTRE, J-P. [I936] (s/f). La trascendencia del ego. Madrid, Síntesis.

[1938] (1995). Esquisse d'une théorie des émotions. Paris: Hermann.

llimard nrf. (I940) L'imaginaire. Paris: Ga-

VASSAllo, S. (20I3) “Acto y libertad. Su emergencia en La trascendencia del ego de J.-P. Sartre", en Bertorello, A.; LuteRAU, L.; MuÑoz: (comps.) Deseo y libertad: Sartre y el Psicoanálisis. Buenos Aires, Letra Viva.

\section{RESEÑA CURRICULAR DEL AUTOR}

Bruno Carignano es psicoanalísta, Doctorando en Cotutela por convenio entre la Université Paris Diderot —COMUE Sorbonne Paris Cité, Centre de recherches psychanalyse, médecine et société (CRPMS) - y la Universidad Nacional de Rosario, Facultad de Psicología, Secretaría de Estudios de Posgrados, Doctorado en Psicología.

Jefe de Trabajos Prácticos concursado de Psicoanálisis II, Facultad de Psicología, UNR.

Profesor Titular concursado en UCES, en las cátedras Psicoanálisis Freud II, Psicoanálisis Escuela Francesa, Taller de Trabajo Integrador Final y Psicopatología II. 